\title{
ОРГАНИЗАЦИОННО-ЭКОНОМИЧЕСКИЕ И АДМИНИСТРАТИВНО-ПРАВОВЫЕ ФАКТОРЫ СТИМУЛИРОВАНИЯ РАЗВИТИЯ ЭКОНОМИКИ РОСТОВСКОЙ ОБЛАСТИ
}

\section{ORGANIZATIONAL-ECONOMIC AND ADMINISTRATIVE-LEGAL FACTORS STIMULATING THE DEVELOPMENT OF THE ECONOMY OF THE ROSTOV REGION}

A. Brik

G. Plohotnikova

Summary. The article analyzes the main indicators of the economic development of the Rostov region at the present stage, examines the dynamics of foreign trade turnover, substantiates organizational, economic and administrative measures aimed at developing the competitive advantages of the regional economy of the Rostov region. The results of the study can be used by public authorities in preparing programs for socio-economic development, investors in managing financial activities, planning investment in the medium and long term.

Keywords: region, Rostov region, regional economy, foreign economic activity, competitiveness.
$\mathbf{M}$ ировая пандемия коронавирусной инфекции оказывает негативное воздействие на экономические и социальные процессы. Резко меняется структура экономики, распадаются старые и формируются новые торговые, производственные взаимосвязи. Указанные процессы затрагивают в том числе Российскую Федерацию. С учётом сказанным, возрастает актуальность и востребованность научных работ, направленных на исследование организационно-экономических и административно-правовые факторов стимулирования социально-экономического развития на региональном уровне.

На сегодняшний день Ростовская область является промышленно и аграрно-развитым субъектом Российской Федерации. На территории региона функционируют хозяйствующие субъекты следующих отраслей промышленности: химическая, машиностроительная, металлургическая, строительная [6, 8]. По численности проживающих граждан, Ростовская область является крупнейшим регионом Юга России. В таблице $1[4,5]$ представлена динамика численности населения Ростовской области.
Брик Анна Дмитриевна

К.ю.н., дочент, ФГБОУВО «Донской государственный аграрный университет», n. Персиановский

brikad@mail.ru

Плохотникова Галина Владимировна

К.э.н., дочент, Новочеркасский инженерномелиоративный институт им. А. К. Кортунова филиал ФГБОУ ВО «Донской государственный аграрный университет», г. Новочеркасск g409zx@yandex.ru

Аннотация. В статье анализируются основные показатели экономического развития Ростовской области на современном этапе, исследуется динамика внешнеторгового оборота, обосновываются организационно-экономические и административно-правовые мероприятия, направленные на развитие конкурентных преимуществ региональной экономики Ростовской области. Результаты исследования могут использоваться органами государственной власти при подготовке программ социально-экономического развития, инвесторами при управлении финансовой деятельностью, планировании капиталовложений в средне- и долгосрочной перспективе.

Ключевые слова: регион, Ростовская область, региональная экономика, внешнеэкономическая деятельность, конкурентоспособность.

Информация, представленная в таблице 1 позволяет сказать о том, что Ростовская область является урбанизированным регионом, т.к. численность граждан, проживающих в городах, существенно превосходит население сельских территорий региона. Необходимо отметить следующие основные тенденции: за период наблюдения отмечается сокращение численности городского (-9,2 тыс. чел.) и сельского населения (-29,0 тыс. чел.) Ростовской области, что в совокупности дало убыль проживающих граждан с 4236,0 тыс. чел. в 2015 г. до 4197,8 тыс. чел. в 2019 г. (-38,2 тыс. чел.).

В таблице 2 [4, 5] представлены основные показатели экономического развития Ростовской области за период 2015-2019 гг.

Анализ информации, представленной в таблице 2, позволяет отметить следующее. Сельское хозяйство является одной из наиболее динамичных отраслей экономики Ростовской области. Производство сельскохозяйственной продукции увеличилось за период 20152019 гг. с 219,0 млрд. руб. до 303,1 млрд. руб. (+84,1 млрд., 
Таблица 1. Динамика численности граждан, проживающих в Ростовской области за период 20152019 гг., тыс. чел.

\begin{tabular}{|c|c|c|c|c|c|c|c|}
\hline \multirow{2}{*}{ Показатель } & \multicolumn{5}{|l|}{ Годы } & \multicolumn{2}{|l|}{ Динамика } \\
\hline & 2015 & 2016 & 2017 & 2018 & 2019 & Тыс. чел. & $\%$ \\
\hline $\begin{array}{l}\text { Численность граждан, проживающих } \\
\text { в городах }\end{array}$ & 2872,1 & 2874,0 & 2871,4 & 2863,7 & 2862,9 & $-9,2$ & $-0,3$ \\
\hline $\begin{array}{l}\text { Численность граждан, проживающих } \\
\text { в сельской местности }\end{array}$ & 1363,9 & 1357,3 & 1349,0 & 1338,6 & 1334,9 & $-29,0$ & $-2,1$ \\
\hline $\begin{array}{l}\text { Всего граждан, проживающих } \\
\text { в регионе }\end{array}$ & 4236,0 & 4231,3 & 4220,4 & 4202,3 & 4197,8 & $-38,2$ & $-0,9$ \\
\hline
\end{tabular}

Таблица 2. Основные показатели экономического развития Ростовской области за период 2015-2019 гг. (в сопоставимых ценах)

\begin{tabular}{|c|c|c|c|c|c|c|c|}
\hline \multirow{2}{*}{ Показатель } & \multicolumn{5}{|l|}{ Годы } & \multicolumn{2}{|l|}{ Динамика } \\
\hline & 2015 & 2016 & 2017 & 2018 & 2019 & Млрд руб. & $\%$ \\
\hline $\begin{array}{l}\text { Производство продукции } \\
\text { растениеводства }\end{array}$ & 146,6 & 175,8 & 177,3 & 184,3 & 239,1 & 92,5 & 63,1 \\
\hline $\begin{array}{l}\text { Производство продукции } \\
\text { животноводства }\end{array}$ & 72,4 & 77,0 & 77,1 & 70,9 & 64,0 & $-8,4$ & $-11,6$ \\
\hline $\begin{array}{l}\text { Производство сельскохозяйственной } \\
\text { продукции }\end{array}$ & 219,0 & 252,8 & 254,4 & 255,2 & 303,1 & 84,1 & 38,4 \\
\hline Оборот розничной торговли & 824,9 & 853,3 & 880,4 & 920,8 & 975,6 & 150,7 & 18,3 \\
\hline $\begin{array}{l}\text { Объём реальных инвестиций } \\
\text { в основные средства }\end{array}$ & 309,4 & 294,5 & 323,9 & 264,9 & 283,0 & $-26,4$ & $-8,5$ \\
\hline $\begin{array}{l}\text { Доходы консолидированного бюджета } \\
\text { Ростовской области }\end{array}$ & 170,8 & 190,9 & 192,2 & 217,3 & 221,4 & 50,6 & 29,6 \\
\hline $\begin{array}{l}\text { Расходы консолидированного бюджета } \\
\text { Ростовской области }\end{array}$ & 185,4 & 186,4 & 190,7 & 209,4 & 226,3 & 40,9 & 22,1 \\
\hline $\begin{array}{l}\text { Сальдо консолидированного бюджета } \\
\text { Ростовской области }\end{array}$ & $-14,6$ & 4,5 & 1,5 & 7,9 & $-4,9$ & & \\
\hline
\end{tabular}

+38,4\%). При этом, отмечается укрепление растениеводческой специализации регионального агропромышленного комплекса. Прирост производства продукции растениеводства составил 92,5 млрд. руб. В тоже время, производство продукции животноводства сократилось на 8,4 млрд. руб.

Оборот розничной торговли увеличился за период наблюдения на 150,7 млрд. руб. В тоже время, отмечается негативная тенденция сокращения объёма капиталовложений в основной капитал с 309,4 млрд. руб. в 2015 г. до 283,0 млрд. руб. в 2019 г. (-26,4 млрд. руб.). Консолидированный бюджет Ростовской области не является сбалансированным. По итогам 2019 г. дефицит составил 4,9 млрд. руб.

Рассмотрим показатели внешнеэкономической деятельности региона. Динамика внешнеторгового оборота Ростовской области за период 2015-2019 гг. представлена в таблице $3[4,5]$.
За период наблюдения Ростовская область укрепила свои позиции на мировом рынке. В частности, наблюдается устойчивое положительное сальдо внешнеторгового оборота региона. Среди положительных тенденций необходимо отметить более высокий темп роста совокупного экспорта (составивший 72,2\% за период 20152019 гг.) по сравнению с импортом, темп роста которого в том же периоде составил 35,1\%. Необходимо отметить увеличение внешнеторгового оборота на 4211,6 млн. долл. США (+60,8\%) за анализируемый период.

Вместе с тем, следует указать на формирующуюся негативную тенденцию. Ежегодные сопоставления показывают, что за период 2015-2018 гг отмечается устойчивый рост всех основных показателей внешнеторговой деятельности, в том числе положительного сальдо внешнеторгового баланса. Однако за период 2018-2019 гг. ситуация изменилась. Наблюдается сокращение показателей внешнеторгового оборота, экспорта, импорта. Указанные обстоятельства аргументируют необходи- 
Таблица 3. Динамика внешнеторгового оборота Ростовской области за период 2015-2019 гг., млн. долл. США (в сопоставимых ценах)

\begin{tabular}{|c|c|c|c|c|c|c|c|}
\hline \multirow[b]{2}{*}{ Показатель } & \multicolumn{5}{|l|}{ Годы } & \multicolumn{2}{|l|}{ Динамика } \\
\hline & 2015 & 2016 & 2017 & 2018 & 2019 & $\begin{array}{l}\text { Млн долл. } \\
\text { США }\end{array}$ & $\%$ \\
\hline \multicolumn{8}{|l|}{ Экспорт } \\
\hline $\begin{array}{l}\text { Страны Содружества } \\
\text { независимых государств }\end{array}$ & 936,4 & 1101,8 & 1366,3 & 1640,8 & 1602,9 & 666,5 & 71,2 \\
\hline Прочие страны & 3868,2 & 4443,9 & 5478,3 & 7420,5 & 6669,0 & 2800,8 & 72,4 \\
\hline Всего & 4804,6 & 5545,7 & 6844,6 & 9061,3 & 8271,9 & 3467,3 & 72,2 \\
\hline \multicolumn{8}{|l|}{ Импорт } \\
\hline $\begin{array}{l}\text { Страны Содружества } \\
\text { независимых государств }\end{array}$ & 723,1 & 642,2 & 839,5 & 1080,2 & 881,7 & 158,6 & 21,9 \\
\hline Прочие страны & 1398,0 & 1544,4 & 2050,0 & 1966,8 & 1983,7 & 585,7 & 41,9 \\
\hline Всего & 2121,1 & 2186,6 & 2889,5 & 3047,0 & 2865,4 & 744,3 & 35,1 \\
\hline \multicolumn{8}{|l|}{ Внешнеторговый оборот } \\
\hline $\begin{array}{l}\text { Страны Содружества } \\
\text { независимых государств }\end{array}$ & 1659,5 & 1744,0 & 2205,8 & 2721,0 & 2484,6 & 825,1 & 49,7 \\
\hline Прочие страны & 5266,2 & 5988,3 & 7528,3 & 9387,3 & 8652,7 & 3386,5 & 64,3 \\
\hline Всего & 6925,7 & 7732,3 & 9734,1 & 12108,3 & 11137,3 & 4211,6 & 60,8 \\
\hline
\end{tabular}

мость реализации организационно-экономических мер, направленных на стимулирование внешнеторговой деятельности Ростовской области.

В завершение необходимо отметить следующее:

1. На современном этапе Ростовская область представляет собой развитый индустриально-аграрный регион Российской Федерации, природно-климатические условия которого создают благоприятные предпосылки для развития сельскохозяйственного производства. Имеющийся у Ростовской области выход к морю, наличие транспортно-логистической инфраструктуры позволяют хозяйствующим субъектом региона активно участвовать во внешнеэкономической деятельности. Дополнительными конкурентными преимуществами региона являются высокий уровень урбанизации, а также научно-образовательный комплекс, позволяющий обеспечить подготовку кадров, необходимых для реализации инвестиционных проектов как в аграрном, так и в промышленном секторах региональной экономики.

2. Установленная выше разнонаправленная динамика развития агропромышленного комплекса региона, выражающаяся, в частности в отмеченных тенденциях роста производства продукции растениеводства при одновременном снижении производства продукции животноводства, свидетельствует о необходимости пересмотра механизма государственной поддержки АПК Ростовской области. По нашему мнению, нецелесообразно тратить денежные средства налогопла- тельщиков на финансирование хозяйствующих субъектов животноводческого комплекса, т.к. совокупность природно-климатических, транспортно-логистических и других факторов формируют благоприятную среду для развития растениеводства. С учётом сказанного, целесообразно сконцентрировать финансовые, материальные, организационные, административные и другие виды ресурсов на развитии естественных конкурентных преимуществ региональной экономики.

3. В целях дальнейшего социально-экономического развития, увеличения темпа роста валового регионального продукта, в Ростовской области целесообразно реализовать комплекс мер, направленных на укрепление её специализации, опирающейся на естественные конкурентные преимущества региона. Речь идёт о формировании институциональных, административно-правовых, организационных предпосылок, во-первых, развития экспортной составляющей агропромышленного производства Ростовской области, во-вторых, снижения издержек хозяйствующих субъектов АПК региона. Согласно действующего законодательства РФ, субъекты Российской Федерации вправе самостоятельно полномочия по регулированию ставок региональных налогов, сроках и порядка их уплаты. С учётом сказанного, одним из действенных инструментов стимулирования инвестиционной активности в регионе, может стать введение нормативно-правовыми актами субъекта РФ отсрочки по уплате некоторых видов региональных налогов в отношении вновь реализуемых 
инвестиционных проектов, отвечающих установленным критериям. Данная мера позволит повысить эффективность капиталовложений за счёт того, что оборотные средства не будут изыматься из проекта в течение определённого гарантированного периода времени. Это позволит повысить финансовую устойчивость, снизить риск неплатёжеспособности [3, 7]. Также целесообразно упростить порядок перево- да земель из одной категории землепользования в другую [1, 2]. В целях стимулирования аграрного экспорта необходимо использовать механизм субсидирования части процентной ставки за счёт средств регионального бюджета по целевым кредитам, привлекаемым для продвижения продукции сельскохозяйственных товаропроизводителей Ростовской области на мировом рынке.

\section{ЛИТЕРАТУРА}

1. Брик А. Д. Об изменениях в правовом регулировании оборота земель сельскохозяйственного назначения / Брик А. Д. // Вестник Донского государственного аграрного университета. 2013. № 2(8). С. 137-146.

2. Брик А. Д. Проблемы оборота земель сельскохозяйственного назначения / Брик А. Д. // Вестник Донского государственного аграрного университета. 2012. № 1(3). C. 103-112.

3. Губачев В.А. Инвестиционная привлекательность и её влияние на конкурентоспособность сельского хозяйства региона / Губачев В. А. // В сборнике: Управление в условиях глобальных мировых трансформаций: экономика, политика, право Сборник научных трудов. 2017. С. 52-55.

4. Официальный сайт Правительства Ростовской области http://www.donland.ru (дата обращения 15 апреля 2020 г.)

5. Официальный сайт территориального органа Росстата по Ростовской области URL: http://rostov.gks.ru/ (дата обращения 1 апреля 2020 г.)

6. Плохотникова Г. В. Глобальное экономическое позиционирование Ростовской области: факторы, тенденции, направления развития / Плохотникова Г. В. // В книге: Современные проблемы управления и регулирования. Монография. Пенза, 2017. С. 104-114.

7. Плохотникова Г.В. Приоритетные направления развития конкурентных преимуществ региона (на примере Ростовской области) / Плохотникова Г.В., Дальченко Е. А. // Экономика и предпринимательство. 2018. № 1 (90). С. 335-337.

8. Ревунов Р. В. Повышение эффективности экономического комплекса Юга России / Ревунов Р. В., Дальченко Е. А. // Императивы, векторы, организационно-экономические решения / Саарбрюкен, 2016.

( Брик Анна Дмитриевна ( brikad@mail.ru ), Плохотникова Галина Владимировна ( g409zx@yandex.ru ). Журнал «Современная наука: актуальные проблемы теории и практики»

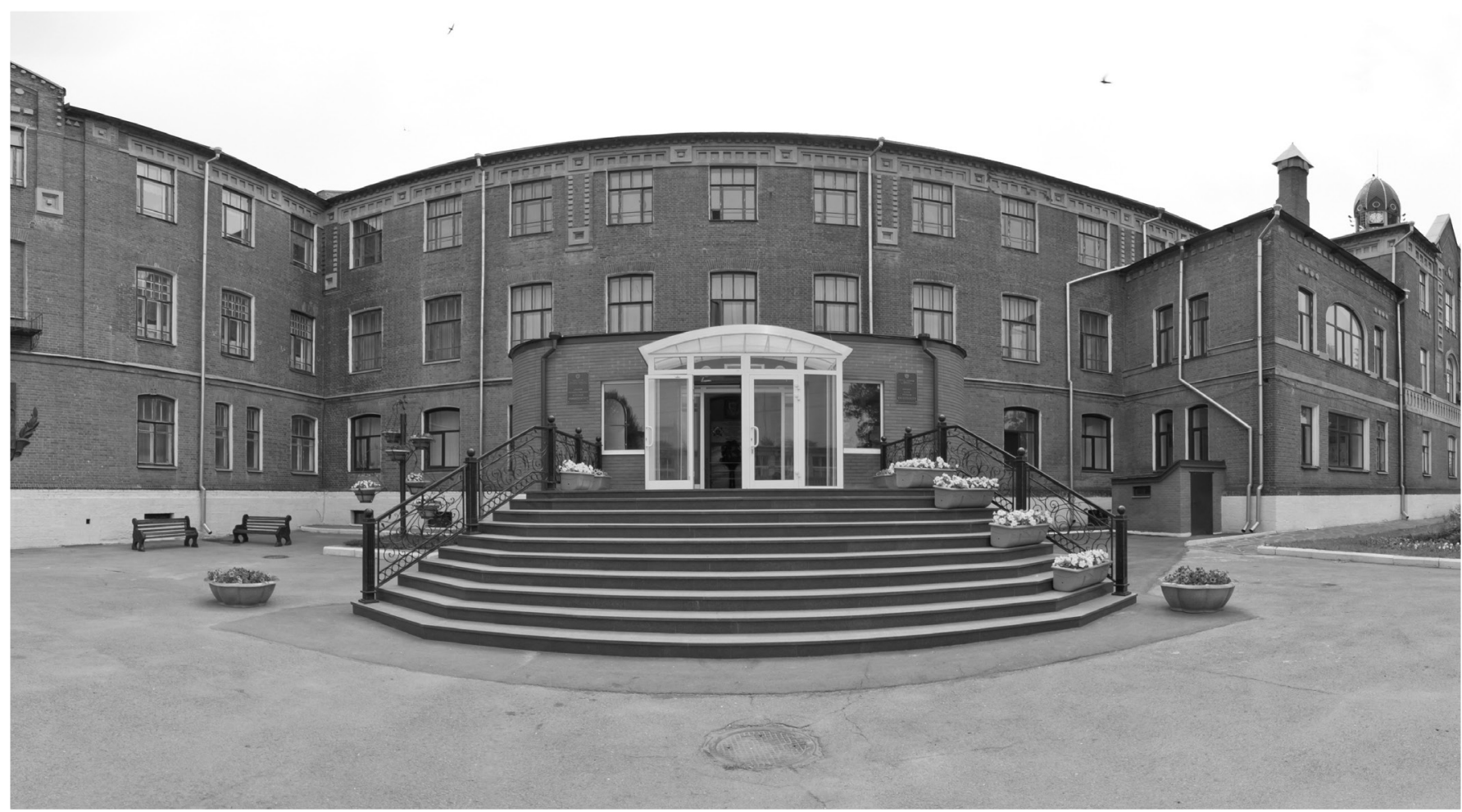

